\title{
Polymorphisms of genes involved in lipid metabolism and risk of chronic kidney disease in Japanese - cross-sectional data from the J-MICC study
}

Asahi Hishida ${ }^{1 *}$, Kenji Wakai ${ }^{1}$, Mariko Naito ${ }^{1}$, Shino Suma ${ }^{1}$, Tae Sasakabe ${ }^{1}$, Nobuyuki Hamajima ${ }^{2}$, Satoyo Hosono ${ }^{3}$, Mikako Horita ${ }^{4}$, Tanvir Chowdhury Turin ${ }^{5,6}$, Sadao Suzuki ${ }^{7}$, Tara Sefanya Kairupan ${ }^{8,9}$, Haruo Mikami ${ }^{10}$, Keizo Ohnaka ${ }^{11}$, Isao Watanabe ${ }^{12}$, Hirokazu Uemura ${ }^{13}$, Michiaki Kubo ${ }^{14}$, Hideo Tanaka ${ }^{3}$, for the J-MICC Study Group

\begin{abstract}
Background: Chronic kidney disease (CKD) is known to be one of the causes of cardiovascular disease and end-stage renal disease. Among the several treatable risk factors of CKD, that of dyslipidemia is relatively controversial. To clarify the association of polymorphisms in genes involved in lipid metabolism with the risk of CKD in the Japanese population, we used cross-sectional data from the Japan Multi-Institutional Collaborative Cohort (J-MICC) Study.

Methods: A total of 3,268 men and women, aged 35-69 years, were selected from J-MICC Study participants for inclusion in this study. Twenty-eight candidate single nucleotide polymorphisms (SNPs) were selected in 17 genes associated with the risk of lipid metabolism disorders, and genotyping of the subjects was conducted using the multiplex PCR-based invader assay. The prevalence of CKD was determined for stages 3-5 (defined as estimated glomerular filtration rate $<60 \mathrm{ml} / \mathrm{min} / 1.73 \mathrm{~m}^{2}$ ).
\end{abstract}

Results: Logistic regression analysis revealed that SNPs APOA5 T - 1131C (rs662799), APOA5 T1259C (rs2266788), TOMM40 A/G (rs157580), and CETP TaqIB (rs708272) were significantly associated with CKD risk in those individuals genotyped, with age- and sex-adjusted odds ratios (ORs) per minor allele (and 95\% confidence intervals (Cls)) of OR 1.22 (95\% Cl: 1.06-1.39), 1.19 (1.03-1.37), 1.27 (1.12-1.45), and 0.81 (0.71-0.92), respectively. Analysis of the gene-environment interaction revealed that body mass index (BMI) was a significant effect modifier for APOA5 T-1131C (rs662799) and a marginally significant effect modifier for APOA5 T/C (rs2266788), with the interaction between $\mathrm{BMI} \geq 30$ and individuals with at least one minor allele of each genotype of OR 10.43 (95\% Cl: 1.29-84.19) and 3.36 (0.87-13.01), respectively.

Conclusions: Four polymorphisms in APOA5, TOMM40, and CETP were shown to be significantly associated with CKD risk, and a significant interaction between the two APOA5 SNPS and BMI on CKD risk was also demonstrated. This suggests the future possibility of personalized risk estimation for this life-limiting disease.

Keywords: Lipid metabolism, Chronic kidney disease, Single nucleotide polymorphism

\footnotetext{
*Correspondence: a-hishi@med.nagoya-u.ac.jp

'Department of Preventive Medicine, Nagoya University Graduate School of Medicine, Nagoya 466-8550, Japan

Full list of author information is available at the end of the article
} 


\section{Background}

Chronic kidney disease (CKD) is emerging as a major public health and financial burden worldwide, and the number of affected patients is increasing in East Asian countries such as Japan, where more than 10 million people currently have CKD stage $\geq 3$. CKD is also known to be a cause of cardiovascular disease (CVD) and endstage renal disease, so prevention of this potentially lifelimiting disease is becoming a pressing issue [1]. CKD has a number of treatable risk factors, such as diabetes mellitus, hypertension, glomerular nephritis, and dyslipidemia [2]. Of these, the effect of dyslipidemia on human CKD risk is relatively controversial, although substantial evidence from animal models is supportive of this association $[3,4]$, suggesting that dyslipidemia plays an important role in the development and progression of CKD. Additionally, data from 4,483 healthy men participating in the Physician's Health Study showed that elevated total cholesterol, high non-high-density lipoprotein (HDL) cholesterol, a high ratio of total cholesterol to HDL cholesterol, and low HDL cholesterol in particular were significantly associated with an increased risk of developing renal dysfunction with an initial creatinine level $<1.5 \mathrm{mg} / \mathrm{dl}$ [5]. Some other reports also suggested that blood lipids modify the decline in renal function as well as hypertension [6,7].

In 2005, we launched the Japan Multi-Institutional Collaborative Cohort (J-MICC) Study, a large genome cohort study to confirm and detect gene-environment interactions in lifestyle-related diseases, particularly cancer $[8,9]$. Considering the potentially important roles of lipid metabolisms in the etiology of CKD, we hypothesized that genetic polymorphisms modulating lipid metabolizing pathways would also affect CKD risk in humans. Accordingly, to clarify the association of polymorphisms in genes involved in lipid metabolism with CKD risk, we examined this in Japanese subjects using the cross-sectional data of the J-MICC Study.

\section{Results}

\section{Subject characteristics and allele frequencies of genes involved in lipid metabolism}

Subject characteristics are summarized by CKD status in Table 1 . The mean age \pm standard deviation was $56.6 \pm$ 8.6 years, and $48.6 \%$ of all subjects were men. Subjects with CKD accounted for $17.3 \%(564 / 3,268)$ of the entire study population. Estimated glomerular filtration rate (eGFR), age, systolic blood pressure, total cholesterol, uric acid, use of anti-hypertensive or lipid-lowering drugs, history of CVD or cerebrovascular disease, and current smokers were all significantly different between subjects with and without CKD.

The genotype frequencies included in the analyses were in accordance with Hardy-Weinberg equilibrium (HWE), except for the following: apolipoprotein A5 gene
(APOA5) G553T (Cys185Gly, rs2075291) $(T$ allele $=0.066$, $\left.X^{2}=4.791, P=0.029\right)$, apolipoprotein $\mathrm{E}$ gene $(A P O E)$ T471C (Cys112Arg, rs429358) $\left(C\right.$ allele $=0.099, X^{2}=$ 6.833, $P=0.009), A P O E \mathrm{~T}-219 \mathrm{G}$ (rs405509) $(G$ allele $=$ 0.307, $\left.\chi^{2}=8.666, P=0.003\right)$, and the translocase of outer mitochondrial membrane 40 homolog gene (TOMM40) $\mathrm{A} / \mathrm{G}(\mathrm{rs} 157580)\left(G\right.$ allele $\left.=0.473, \mathrm{X}^{2}=6.626, P=0.010\right)$. The genotype call rate was more than $99.6 \%$ for all individuals with serum creatinine ( $\mathrm{SCr})$ data $(n=3,326)$.

\section{Polymorphisms involved in lipid metabolism and risk of CKD}

The potential confounders tested did not fulfill the significance criteria of change in estimate (CIE) $>0.1(10 \%)$, so we adopted the odds ratios (ORs) adjusted only for age and sex. Logistic regression analysis revealed that $A P O A 5$ $\mathrm{T}-1131 \mathrm{C}$ (rs662799), APOA5 T1259C (rs2266788), TOMM40 A/G (rs157580), and cholesterol ester transfer protein gene (CETP) TaqIB (rs708272) were significantly associated with the risk of CKD, with age- and sexadjusted ORs (aORs) and 95\% confidence intervals (95\% CIs) of aOR 1.22 (95\% CI: 1.06-1.39), 1.19 (1.03-1.37), 1.27 (1.12-1.45), and 0.81 (0.71-0.92), respectively (Table 2). Because the two APOA5 SNPs (rs662799 and rs2266788) are reported to be closely linked, we also conducted haplotype analysis for these loci. This confirmed that the two SNPs were tightly linked, with linkage disequilibrium (LD) coefficients $D^{\prime}=0.99, r^{2}=0.72$, while the $C$ - $C$ haplotype was found to be significantly associated with an increased risk of CKD (aOR 1.18 (95\% CI: 1.02-1.36)) (Additional file 1: Table S1). We also conducted the analysis of serum lipid levels according to these genotypes found to be significant, as it may provide important information about the possible underlying mechanisms for the associations found (Additional file 2: Table S2).

To detect the lifestyle factors involved in gene-environment interactions with the genes significantly associated with CKD risk, we evaluated the interaction term for effect measure modification using the Breslow-Day (B-D) test of homogeneity with $\alpha=0.05$. Body mass index (BMI) was extracted as the only covariate that significantly contributed to the outcome prediction. Gene-environment interactions were then assessed by the logistic model incorporating a multiplicative interaction term, which revealed that BMI was a significant effect modifier for APOA5 T-1131C (rs662799) and a marginally significant effect modifier of APOA5 T1259C (rs2266788). The interaction between high BMI $(\geq 30)$ and individuals with at least one minor allele of each SNP was OR 10.43 (95\% CI: 1.29-84.19) and 3.36 (0.87-13.01), respectively. Stratified analyses of the CKD risk for the APOA5 T-1131C (rs662799) SNP by BMI resulted in a strikingly higher OR for individuals with at least one $C$ allele of APOA5 T-1131C (rs662799) when only those 
Table 1 Comparison of characteristics between subjects with and without CKD $(n=3,268)$

\begin{tabular}{|c|c|c|c|}
\hline & $\begin{array}{l}\text { CKD (+) } \\
(n=564)\end{array}$ & $\begin{array}{c}\text { CKD (-) } \\
(n=2,704)\end{array}$ & $P$ \\
\hline CKD stage $3\left(\mathrm{eGFR}<60 \mathrm{ml} / \mathrm{min} / 1.73 \mathrm{~m}^{2}\right)$ & $561(99.5 \%)$ & - & \\
\hline Stage $4(e G F R<30)$ & $0(0 \%)$ & - & - \\
\hline Stage 5 (eGFR < 15) & $3(0.5 \%)$ & - & \\
\hline eGFR $\left(\mathrm{ml} / \mathrm{min} / 1.73 \mathrm{~m}^{2}\right)$ & $53.7 \pm 6.0$ & $78.3 \pm 12.5$ & $<0.001$ \\
\hline Age (years) & $60.4 \pm 7.2$ & $55.9 \pm 8.7$ & $<0.001$ \\
\hline Male & $260(46.1 \%)$ & $1,327(49.1 \%)$ & 0.198 \\
\hline Body mass index & $23.5 \pm 3.1$ & $23.4 \pm 3.3$ & 0.413 \\
\hline Systolic blood pressure $(\mathrm{mm} \mathrm{Hg})$ & $130.1 \pm 19.8$ & $128.1 \pm 19.4$ & 0.029 \\
\hline Diastolic blood pressure (mm Hg) & $78.8 \pm 12.4$ & $78.6 \pm 11.9$ & 0.746 \\
\hline Use of anti-hypertensive drugs & $149(26.4 \%)$ & $486(18.0 \%)$ & $<0.001$ \\
\hline Fasting plasma glucose (mg/dL) & $98.8 \pm 22.1$ & $100.0 \pm 20.8$ & 0.291 \\
\hline $\mathrm{HbA1c}(\%)$ & $5.22 \pm 0.70$ & $5.22 \pm 0.66$ & 0.942 \\
\hline Use of glucose-lowering drugs & $31(5.5 \%)$ & $110(4.1 \%)$ & 0.129 \\
\hline Total cholesterol (mg/dL) & $218.2 \pm 34.0$ & $211.1 \pm 33.9$ & $<0.001$ \\
\hline HDL cholesterol (mg/dL) & $62.0 \pm 15.9$ & $63.3 \pm 16.3$ & 0.071 \\
\hline Triglyceride $(\mathrm{mg} / \mathrm{dL})^{*}$ & $106(76.5-151)$ & $104(74-154)$ & 0.992 \\
\hline Use of lipid-lowering drugs & $70(12.4 \%)$ & $225(8.3 \%)$ & 0.002 \\
\hline Uric acid (mg/dL) & $5.53 \pm 1.47$ & $5.10 \pm 1.33$ & $<0.001$ \\
\hline History of cardiovascular diseases & $34(6.0 \%)$ & $80(3.0 \%)$ & $<0.001$ \\
\hline History of cerebrovascular diseases & $29(5.1 \%)$ & $52(1.9 \%)$ & $<0.001$ \\
\hline Current smokers & $69(12.2 \%)$ & $484(17.9 \%)$ & 0.001 \\
\hline Current drinkers & $295(52.3 \%)$ & $1,510(55.8 \%)$ & 0.138 \\
\hline
\end{tabular}

Values are expressed as means \pm standard deviation, $\mathrm{n}(\%)$, or median (interquartile range). CKD: chronic kidney disease. CKD was defined as estimated glomerular filtration rate $<60 \mathrm{ml} / \mathrm{min} / 1.73 \mathrm{~m}^{2}$.

*Non-fasting.

individuals with $\mathrm{BMI} \geq 30$ were included (OR 12.39 (95\% CI: 1.55-99.09); Table 3). Additionally, we conducted an exhaustive investigation of the gene-environment interactions for all SNPs tested, which revealed several statistically significant interactions in addition to the one described above (Additional file 3: Table S3).

\section{Discussion}

The present study examined the associations between polymorphisms in genes involved in lipid metabolism and the risk of CKD in the Japanese population, and identified a total of four SNPs (two in APOA5 (T - 1131C [rs662799] and T1259C [rs2266788]), TOMM40 A/G (rs157580), and CETP TaqIB (G > A) (rs708272)) that were significantly associated with CKD risk. While the functional implications of some of these polymorphisms are well-known, others have not yet been sufficiently clarified.

The APOA5 SNP T-1131C (rs662799) is located in the $A P O A 5$ promoter region and is thought to modulate gene expression, with minor allele carriers found to have high triglyceride levels. It is also reported to be in strong LD with the APOA5 SNP rs2266788 [10,11]. There exist a considerable number of reports supporting these effects of APOA5 SNPs on blood triglyceride levels $[10,12,13]$, and given the potentially important roles of blood triglyceride concentrations in the development of human CKD [13,14], the modulation of blood triglyceride levels due to these APOA5 SNPs may contribute to the genesis of CKD in humans. The result of our haplotype analysis of APOA5 SNPs (rs662799 and rs2266788) suggested the potentially substantial role of rs662779. As this rs662779 (T-1131C) SNP in APOA5 is located in the promoter region of the $A P O A 5$ gene, it is speculated to modulate the expression of APOA5, although further biological investigations will be required to confirm it.

TOMM4O is located within $15 \mathrm{~kb}$ of APOE, and this is reflected by the strong LD of TOMM40 polymorphisms, including SNP rs157580, with the $\varepsilon 4$ allele. TOMM40 polymorphisms are therefore very interesting targets to study in association with human disorders such as Alzheimer's disease [15]. A recent genome-wide association study revealed that the TOMM40 SNP rs157580 was significantly associated with low triglyceride levels [16], although another study reported a significant association 
Table 2 Polymorphisms in lipid metabolizing genes and risk of CKD

\begin{tabular}{|c|c|c|c|c|c|}
\hline Polymorphism & Genotype & $\begin{array}{l}\text { CKD (+) } \\
(n=564)\end{array}$ & $\begin{array}{c}\text { CKD (-) } \\
(n=2,704)\end{array}$ & $\begin{array}{c}\text { Per allele } \\
\text { aOR }(95 \% \mathrm{Cl})^{*}\end{array}$ & $P$ \\
\hline APOA1 Ala61Thr (G219A) & $G / G$ & $506(89.7 \%)$ & $2,423(89.6 \%)$ & & \\
\hline \multirow[t]{2}{*}{ (rs12718465) } & $A / G$ & $56(9.9 \%)$ & $268(9.9 \%)$ & $0.98(0.74-1.31)$ & 0.901 \\
\hline & $A / A$ & $2(0.4 \%)$ & $13(0.5 \%)$ & & \\
\hline APOA5 G553T (Cys185Gly) & $G / G$ & $483(85.6 \%)$ & 2,375 (87.8\%) & & \\
\hline \multirow[t]{2}{*}{ (rs2075291) } & $G / T$ & 79 (14.0\%) & $309(11.4 \%)$ & $1.12(0.87-1.43)$ & 0.378 \\
\hline & $T / T$ & $2(0.4 \%)$ & $20(0.7 \%)$ & & \\
\hline APOA5 T-1131C & $T / T$ & $221(39.2 \%)$ & 1,197 (44.3\%) & & \\
\hline \multirow[t]{2}{*}{ (rs662799) } & $C / T$ & $258(45.7 \%)$ & 1,183 (43.8\%) & $1.22(1.06-1.39)$ & 0.004 \\
\hline & $C / C$ & $85(15.1 \%)$ & $324(12.0 \%)$ & & \\
\hline APOA5 C/A & $C / C$ & $210(37.2 \%)$ & $1,028(38.0 \%)$ & & \\
\hline \multirow[t]{2}{*}{ (rs6589567) } & $C / A$ & $264(46.8 \%)$ & $1,241(45.9 \%)$ & $1.03(0.90-1.17)$ & 0.684 \\
\hline & $A / A$ & $90(16.0 \%)$ & $435(16.1 \%)$ & & \\
\hline APOA5 T1259C & $T / T$ & $282(50.0 \%)$ & $1,437(53.1 \%)$ & & \\
\hline \multirow[t]{2}{*}{ (rs2266788) } & $T / C$ & $224(39.7 \%)$ & $1,059(39.2 \%)$ & $1.19(1.03-1.37)$ & 0.019 \\
\hline & $C / C$ & $58(10.3 \%)$ & $208(7.7 \%)$ & & \\
\hline$A P O B A / G$ & $A / A$ & $308(54.6 \%)$ & $1,421(52.6 \%)$ & & \\
\hline \multirow[t]{2}{*}{ (rs673548) } & $A / G$ & $210(37.2 \%)$ & 1,056 (39.1\%) & $0.95(0.82-1.10)$ & 0.490 \\
\hline & $G / G$ & $46(8.2 \%)$ & $227(8.4 \%)$ & & \\
\hline APOE Arg158Cys (C609T) & $C / C$ & $523(92.7 \%)$ & $2,472(91.4 \%)$ & & \\
\hline \multirow[t]{2}{*}{ (rs7412) } & $C / T$ & $40(7.1 \%)$ & $226(8.4 \%)$ & $0.82(0.58-1.15)$ & 0.255 \\
\hline & $T / T$ & $1(0.2 \%)$ & $6(0.2 \%)$ & & \\
\hline APOE Cys112Arg (T471C) & $T / T$ & $469(83.2 \%)$ & $2,200(81.4 \%)$ & & \\
\hline \multirow[t]{2}{*}{ (rs429358) } & $T / C$ & $88(15.6 \%)$ & $466(17.2 \%)$ & $0.91(0.73-1.13)$ & 0.388 \\
\hline & $C / C$ & $7(1.2 \%)$ & $38(1.4 \%)$ & & \\
\hline APOE T-219G & $T / T$ & $290(51.4 \%)$ & $1,317(48.7 \%)$ & & \\
\hline \multirow[t]{2}{*}{ (rs405509) } & $T / G$ & $228(40.4 \%)$ & $1,090(40.3 \%)$ & $0.90(0.78-1.03)$ & 0.124 \\
\hline & $G / G$ & $46(8.2 \%)$ & $297(11.0 \%)$ & & \\
\hline APOE cluster A/G & $A / A$ & $452(80.1 \%)$ & $2,155(79.7 \%)$ & & \\
\hline \multirow[t]{2}{*}{ (rs4420638) } & $A / G$ & $104(18.4 \%)$ & $509(18.8 \%)$ & $0.97(0.79-1.20)$ & 0.798 \\
\hline & $G / G$ & $8(1.4 \%)$ & $40(1.5 \%)$ & & \\
\hline TOMM40 A/G & $A / A$ & $118(20.9 \%)$ & 825 (30.5\%) & & \\
\hline \multirow[t]{2}{*}{ (rs157580) } & $A / G$ & $299(53.0 \%)$ & $1,257(46.5 \%)$ & $1.27(1.12-1.45)$ & $<0.001$ \\
\hline & $G / G$ & $147(26.1 \%)$ & $622(23.0 \%)$ & & \\
\hline$H M G C R$ G/A & $G / G$ & $163(28.9 \%)$ & $736(27.2 \%)$ & & \\
\hline \multirow[t]{2}{*}{ (rs3846662) } & $G / A$ & $278(49.3 \%)$ & $1,326(49.0 \%)$ & $0.91(0.80-1.04)$ & 0.162 \\
\hline & $A / A$ & $123(21.8 \%)$ & $642(23.7 \%)$ & & \\
\hline$L P L G / A$ & $G / G$ & $366(64.9 \%)$ & $1,797(66.5 \%)$ & & \\
\hline \multirow[t]{2}{*}{ (rs331) } & $G / A$ & $177(31.4 \%)$ & $816(30.2 \%)$ & $1.04(0.88-1.22)$ & 0.681 \\
\hline & $A / A$ & $21(3.7 \%)$ & $91(3.4 \%)$ & & \\
\hline LPL G1791C (Ser474Stop) & $G / G$ & $423(75.0 \%)$ & 2,083 (77.0\%) & & \\
\hline \multirow[t]{2}{*}{ (rs328) } & $G / C$ & $131(23.2 \%)$ & $579(21.4 \%)$ & $1.07(0.89-1.30)$ & 0.466 \\
\hline & $C / C$ & $10(1.8 \%)$ & $42(1.6 \%)$ & & \\
\hline
\end{tabular}


Table 2 Polymorphisms in lipid metabolizing genes and risk of CKD (Continued)

\begin{tabular}{|c|c|c|c|c|c|}
\hline NR1H3 G/A & $G / G$ & $301(53.4 \%)$ & $1,512(55.9 \%)$ & & \\
\hline \multirow[t]{2}{*}{ (rs7120118) } & $G / A$ & $224(39.7 \%)$ & $1,027(38.0 \%)$ & $1.12(0.97-1.31)$ & 0.125 \\
\hline & $A / A$ & $39(6.9 \%)$ & $165(6.1 \%)$ & & \\
\hline NR1H3 A/G & $A / A$ & $299(53.0 \%)$ & $1,524(56.4 \%)$ & & \\
\hline \multirow[t]{2}{*}{ (rs2167079) } & $A / G$ & $227(40.2 \%)$ & $1,017(37.6 \%)$ & $1.14(0.99-1.33)$ & 0.078 \\
\hline & $G / G$ & $38(6.7 \%)$ & $163(6.0 \%)$ & & \\
\hline MTNRIB A/G & $A / A$ & $250(44.3 \%)$ & $1,245(46.0 \%)$ & & \\
\hline \multirow[t]{2}{*}{ (rs1447352) } & $A / G$ & $247(43.8 \%)$ & $1,176(43.5 \%)$ & $1.06(0.92-1.22)$ & 0.392 \\
\hline & $G / G$ & $67(11.9 \%)$ & $283(10.5 \%)$ & & \\
\hline FADS2 C/T & $\mathrm{C} / \mathrm{C}$ & $227(40.2 \%)$ & $979(36.2 \%)$ & & \\
\hline \multirow[t]{2}{*}{ (rs174570) } & $\mathrm{C} / T$ & $250(44.3 \%)$ & 1,266 (46.8\%) & $0.91(0.80-1.04)$ & 0.167 \\
\hline & $T / T$ & 87 (15.4\%) & $459(17.0 \%)$ & & \\
\hline KCNJ11 A1577G (lle337Val) & $A / A$ & $240(42.6 \%)$ & $1,068(39.5 \%)$ & & \\
\hline \multirow[t]{2}{*}{ (rs5215) } & $A / G$ & $241(42.7 \%)$ & $1,274(47.1 \%)$ & $0.95(0.83-1.09)$ & 0.485 \\
\hline & $G / G$ & $83(14.7 \%)$ & $362(13.4 \%)$ & & \\
\hline TMEM57 A/G & $A / A$ & $256(45.4 \%)$ & $1,186(43.9 \%)$ & & \\
\hline \multirow[t]{2}{*}{ (rs10903129) } & $A / G$ & $254(45.0 \%)$ & $1,234(45.6 \%)$ & $0.90(0.78-1.04)$ & 0.168 \\
\hline & $G / G$ & $54(9.6 \%)$ & $284(10.5 \%)$ & & \\
\hline DOCK7 A/C & $A / A$ & $347(61.5 \%)$ & $1,542(57.0 \%)$ & & \\
\hline \multirow[t]{2}{*}{ (rs1167998) } & $A / C$ & $188(33.3 \%)$ & 996 (36.8\%) & $0.86(0.74-1.01)$ & 0.061 \\
\hline & $C / C$ & $29(5.1 \%)$ & $166(6.1 \%)$ & & \\
\hline CELSR2 C/T & $C / C$ & $516(91.5 \%)$ & $2,413(89.2 \%)$ & & \\
\hline \multirow[t]{2}{*}{ (rs4970834) } & $C / T$ & $46(8.2 \%)$ & $280(10.4 \%)$ & $0.79(0.58-1.07)$ & 0.133 \\
\hline & $T / T$ & $2(0.4 \%)$ & $11(0.4 \%)$ & & \\
\hline LIPC Val95Met (G340A) & $G / G$ & $342(60.6 \%)$ & 1,616 (59.8\%) & & \\
\hline \multirow[t]{2}{*}{ (rs6078) } & $G / A$ & $193(34.2 \%)$ & 945 (34.9\%) & $0.96(0.82-1.13)$ & 0.643 \\
\hline & $A / A$ & $29(5.1 \%)$ & $143(5.3 \%)$ & & \\
\hline LIPC T-514C & $T / T$ & $132(23.4 \%)$ & 731 (27.0\%) & & \\
\hline \multirow[t]{2}{*}{ (rs1800588) } & $T / C$ & $290(51.4 \%)$ & 1,353 (50.0\%) & $1.10(0.97-1.26)$ & 0.143 \\
\hline & $C / C$ & $142(25.2 \%)$ & $620(22.9 \%)$ & & \\
\hline CETP TaqlB $(\mathrm{G}>\mathrm{A})$ & $G / G$ & $234(41.5 \%)$ & 934 (34.5\%) & & \\
\hline \multirow[t]{2}{*}{ (rs708272) } & $G / A$ & $251(44.5 \%)$ & 1,315 (48.6\%) & $0.81(0.71-0.92)$ & 0.002 \\
\hline & $A / A$ & 79 (14.0\%) & $455(16.8 \%)$ & & \\
\hline CETP G/T & $G / G$ & $372(66.0 \%)$ & $1,692(62.6 \%)$ & & \\
\hline \multirow[t]{2}{*}{ (rs3764261) } & $\mathrm{G} / \mathrm{T}$ & $170(30.1 \%)$ & $872(32.2 \%)$ & $0.86(0.73-1.01)$ & 0.068 \\
\hline & $T / T$ & $22(3.9 \%)$ & $140(5.2 \%)$ & & \\
\hline CETP lle405Val $(G>A)$ & $G / G$ & 147 (26.1\%) & $753(27.8 \%)$ & & \\
\hline \multirow[t]{2}{*}{ (r55882) } & $G / A$ & $277(49.1 \%)$ & $1,312(48.5 \%)$ & $1.06(0.93-1.20)$ & 0.403 \\
\hline & $A / A$ & $140(24.8 \%)$ & $639(23.6 \%)$ & & \\
\hline CETP A-629C & $A / A$ & $162(28.7 \%)$ & 825 (30.5\%) & & \\
\hline \multirow[t]{2}{*}{ (rs1800775) } & $A / C$ & 279 (49.5\%) & $1,366(50.5 \%)$ & $1.10(0.96-1.25)$ & 0.174 \\
\hline & $C / C$ & $123(21.8 \%)$ & $513(19.0 \%)$ & & \\
\hline
\end{tabular}


Table 3 Stratified analyses for the CKD risk associated with APOA5 polymorphisms by BMI levels

\begin{tabular}{|c|c|c|c|c|c|c|c|c|}
\hline \multicolumn{2}{|c|}{$\begin{array}{l}\text { Proportion of minor heterozygous plus homozygous } \\
\text { (among subjects with all genotypes) }\end{array}$} & \multicolumn{2}{|c|}{$\begin{array}{l}\text { CKD (+) } \\
(n=564)\end{array}$} & \multicolumn{2}{|c|}{$\begin{array}{c}\text { CKD (-) } \\
(\mathrm{n}=2,704)\end{array}$} & \multirow[t]{2}{*}{$\mathrm{OR}^{*}$} & \multirow[t]{2}{*}{$95 \% \mathrm{Cl}^{*}$} & \multirow[t]{2}{*}{$P_{\text {interaction }} \#$} \\
\hline Genotype & BMI & $\mathrm{N}$ & $(\%)$ & $\mathrm{N}$ & $(\%)$ & & & \\
\hline \multicolumn{9}{|c|}{ APOA5 T-1131C } \\
\hline \multicolumn{9}{|l|}{ (rs662799) } \\
\hline & $\geq 30$ & $15 / 16$ & (93.8) & $54 / 95$ & $(56.8)$ & 12.39 & $1.55-99.09$ & \\
\hline & $<30$ & $328 / 548$ & (59.9) & $1,453 / 2,609$ & $(55.7)$ & 1.21 & $0.999-1.47$ & 0.028 \\
\hline \multicolumn{9}{|c|}{ APOA5 T1259C } \\
\hline \multicolumn{9}{|l|}{ (rs2266788) } \\
\hline & $\geq 30$ & $13 / 16$ & (81.3) & $50 / 95$ & (52.6) & 3.68 & $0.97-13.93$ & \\
\hline & $<30$ & $269 / 548$ & $(49.1)$ & $1,217 / 2,609$ & $(46.6)$ & 1.14 & $0.95-1.38$ & 0.079 \\
\hline
\end{tabular}

*aOR: adjusted odds ratio (adjusted for age and sex); $95 \% \mathrm{Cl}: 95 \%$ confidence interval.

\#OR for interaction $=10.43$ (95\% Cl: 1.29-84.19) for APOA5 rs662799, and 3.36 (95\% Cl: 0.87-13.01) for APOA5 rs 2266788.

between the TOMM40 rs157580 minor $(G)$ allele and increased levels of triglycerides in the Chinese population [17]. Given that population-specific effects appear to exist between different ethnicities in East Asian countries for the same polymorphism [18], our present finding may provide valuable information for future genetic investigations and help prevent publication bias [19].

The CETP TaqI B polymorphism was previously shown to be associated with an effect on HDL cholesterol concentrations [20], as well as subsequent CVD risk [21], which is thought to result from LD between this SNP and an as yet unknown functional mutation in the regulatory region of CETP [22]. The functional roles of this CETP SNP in the regulation of human blood cholesterol levels have been well established by a number of previous studies $[23,24]$. Taking into considerations the important roles of blood cholesterol levels in the risk of renal dysfunction, this CETP SNP is considered to be involved in the CKD development through the modulation of blood cholesterol concentrations.

To date, only a few associations between SNPs in lipid metabolizing genes and CKD risk have been reported, with recent studies reporting a role for apolipoprotein L1 variants in the risk and progression of CKD in African American populations [25,26], and associations of the apolipoprotein A1 gene (APOA1) and APOA5 with CKD risk. Associations between the four SNPs and CKD risk have not previously been reported, so this study provides novel evidence for the effect of genetic variations in these genes involved in lipid metabolism and CKD risk. Moreover, a previous significant association observed between APOE rs405509 and CKD risk was not replicated in the present study. The associations of some, but not all, of the SNPs in our study with CKD followed a similar trend to that previously reported for CVD [27,28], which might be expected given that $\mathrm{CKD}$ is considered to be a form of CVD. The differences could reflect the existence of etiologies specific to each vascular disease, and different gene-environment or gene-gene interactions between races/ethnicities. Nevertheless, the present research appears to confirm the previously reported findings of the possible influence of lipid disorders on the risk of CKD in humans $[3,22]$.

SNPs shown to be marginally significant in the present study, liver X receptor-alpha gene (NRIH3) rs2167079, dedicator of cytokinesis 7 gene (DOCK7) rs1167998, and CETP rs70827, suggest a possible involvement of these genes in CKD development. NRIH3 inhibits cholesterol absorption, while CETP mediates the exchange of lipids between lipoproteins, resulting in the net transfer of cholesteryl ester from HDL cholesterol to other lipoproteins. Considering the important roles of these genes in lipid metabolism and subsequent CKD onset, the involvement of their functional polymorphisms in CKD risk seems biologically plausible. However, their marginal significance could have been detected as a result of a type I error, which necessitates further investigation with sufficiently larger sample sizes. The remaining SNPs found not to be associated with CKD risk may not play a major role in CKD development, thus discouraging us from their further investigation.

One of the most marked as well as important findings of the present study is the significant interaction between the APOA5 SNP and BMI on CKD risk, considering its possible future application in the personalized prevention of CKD. BMI can be regarded as a convenient proxy for energy intake and consumption, as demonstrated by the association between dietary fat and obesity [29], which was represented in a study of the interaction between a polymorphism in the nitric oxide synthase 3 (NOS3) gene and BMI on the risk of type 2 diabetes [30] and in other studies [18]. APOA5 polymorphisms have previously been reported to be associated with elevated serum triglyceride levels by several studies $[10,12,13]$, and an interaction between the APOA5 polymorphism and BMI on high serum triglyceride levels was reported in the East Asian 
population [18]. Taking these findings into consideration, we speculate that the synergistic effect of obesity and dyslipidemia caused by APOA5 polymorphisms may confer the increased risk of CKD.

Our additional exhaustive investigations of the geneenvironment interactions using all polymorphisms tested revealed several statistically significant associations. Although we didn't take all these interactions into further considerations in the present study, these findings may suggest the way for our future investigations.

The present study has several potential limitations. Serum lipid levels, such as cholesterol and/or triglyceride, could be considered as covariates to be adjusted; however, they can also be regarded as causal intermediates that link the polymorphisms involved in lipid metabolism and CKD risk. Therefore, because adjusting for even a partially causal intermediate phenotype would incorrectly remove a true association and potentially bias the true association [31], we chose not to adjust for these variables in this study. Second, although the genotype frequencies of some of the SNPs investigated significantly deviated from HWE, the actual differences in the number of subjects for all genotypes compared with that expected from the equilibrium were small (up to $2.5 \%$ ), or the deviation was caused by the relatively small frequency of the minor allele $(<10 \%)$. Increasing the sample size may have resulted in more robust findings, but it was not easy to do this because of study design constraints. Third, we chose not to adopt the correction of multiple comparisons by Bonferroni procedures because this study was conducted under an exploratory context, and because such adjustments can be regarded as too conservative [32]. Fourth, all CKD cases were diagnosed from $\mathrm{SCr}$ data, which potentially differ from the actual GFR based on renal measurements, so could have diluted the effect of each genotype on CKD risk. Finally, albuminuria was not detected in the present study. Further investigations with improved study designs are therefore required.

\section{Conclusions}

The present study found that two APOA5 polymorphisms ( $\mathrm{T}$ - 1131C [rs662799] and T1259C [rs2266788]), as well as TOMM40 $\mathrm{A} / \mathrm{G}$ (rs157580) and CETP TaqIB $(\mathrm{G}>\mathrm{A})$ (rs708272) were significantly associated with CKD risk in the Japanese population. A significant interaction between the APOA5 T - 1131C SNP and BMI on CKD risk was also demonstrated, indicating the future possibility of personalized risk estimation for this life-limiting disease.

\section{Methods}

\section{Study subjects}

Subjects were participants of the J-MICC Study, initially conducted in 10 areas of Japan, in which around 75,000 voluntarily enrolled participants aged 35-69 years provided blood samples, health check-up data, and lifestyle data through a questionnaire after providing their written informed consent [8].

In the present analysis, 4,519 randomly selected participants (about 500 subjects from each of the 10 areas) were analyzed for whom 108 selected polymorphisms had been genotyped [9]. Of these individuals, six were excluded because of ineligibility or withdrawal from the study. $\mathrm{SCr}$ had been measured in 3,326 respondents from eight of the 10 areas of Japan. Of these, 58 were excluded because of genotyping failure, and the remaining 3,268 were included in the analyses. Informed consent was obtained from all subjects and the study protocol was approved by the Institutional Review Board (IRB) of Nagoya University Graduate School of Medicine (IRB approval no. 253-6) and the affiliated Medical Universities.

\section{Evaluation of lifestyle exposure}

Lifestyle exposures were evaluated by a self-administered questionnaire that was checked by trained staff. The questionnaire included items on smoking status, alcohol consumption, and medical history. Smoking status was classified as current, former, or never, and the level of exposure was evaluated in pack-years. Former smokers were defined as people who had quit smoking for at least 1 year. Alcohol consumption for each type of beverage was determined by average intake frequency and quantity, then converted into the Japanese sake unit gou $(180 \mathrm{ml})$, which is equivalent to $23 \mathrm{~g}$ of ethanol. The participants were categorized into non-habitual drinkers, habitual drinkers who drank less than 1 gou per day, and those who drank at least 1 gou per day; the latter two groups were coded as indicator variables. Intakes of energy and macronutrients were estimated based on responses to a food frequency questionnaire (FFQ), for which its reproducibility and validity to estimate nutrient intakes had been tested and confirmed [33-36]. Correlation coefficients between the FFQ and 3-day food records were 0.49 for energy, 0.61 for \% energy from fat, and 0.86 for $\%$ energy from carbohydrate in men. The corresponding figures in women were $0.44,0.48$, and 0.66 , respectively [35].

\section{eGFR and definitions of CKD}

SCr was measured in all participants using an enzymatic method. The eGFR of each participant was calculated based on $\mathrm{SCr}$, age, and sex using the following Japanese eGFR equation proposed by the Japanese Society of Nephrology [37]: eGFR $\left(\mathrm{ml} / \mathrm{min} / 1.73 \mathrm{~m}^{2}\right)=194 \times \mathrm{SCr}$ $(\mathrm{mg} / \mathrm{dl})^{-1.094} \times$ age $^{-0.287}(\times 0.739$ if female $)$. The prevalence of CKD was determined for CKD stages 3-5 (defined as eGFR $<60 \mathrm{ml} / \mathrm{min} / 1.73 \mathrm{~m}^{2}$ ). 


\section{Selection of SNPs}

We selected 28 candidate SNPs in 17 genes based on the notion that they are well characterized and reported to be associated with the risk of lipid metabolism disorders using public databases such as PubMed and Online Mendelian Inheritance in Man. The selected SNPs were as follows: APOA1 Ala61Thr (G219A) (rs12718465), APOA5 G553T (Cys185Gly) (rs2075291), APOA5 T$1131 \mathrm{C}$ (rs662799), APOA5 C/A (rs6589567), APOA5 T1259C (rs2266788), apolipoprotein B gene $(A P O B) \mathrm{A} / \mathrm{G}$ (rs673548), APOE Arg158Cys (C609T) (rs7412), APOE Cys112Arg (T471C) (rs429358), APOE T - 219G (rs405509), APOE cluster A/G (rs4420638), TOMM40 A/G (rs157580), 3-hydroxy-3-methylglutaryl-CoA reductase gene (HMGCR) G/A (rs3846662), lipoprotein lipase gene ( $L P L)$ G/A (rs331), LPL G1791C (Ser474Stop) (rs328), NR1H3 G/A (rs7120118), NR1H3 A/G (rs2167079), melatonin receptor $1 \mathrm{~B}$ gene $(M T N R 1 B) \mathrm{A} / \mathrm{G}$ (rs1447352), fatty acid desaturase 2 gene (FADS2) C/T (rs174570), potassium channel, subfamily J, member 11 gene (KCNJ11) A1577G (Ile337Val) (rs5215), macoilin gene (TMEM57) A/G (rs10903129), DOCK7 A/C (rs1167998), cadherin gene (CELSR2) C/T (rs4970834), hepatic lipase gene (LIPC) Val95Met (G340A) (rs6078), LIPC T - 514C (rs1800588), CETP TaqIB (G > A) (rs708272), CETP G/T (rs3764261), CETP Ile405Val (G > A) (rs5882), and CETP A -629C (rs1800775).

\section{Genotyping}

DNA was extracted from buffy coat using a BioRobot ${ }^{\oplus}$ M48 Workstation (QIAGEN, Tokyo, Japan), or from whole blood samples using an automatic nucleic acid isolation system (NA-3000, Kurabo Industries Ltd., Osaka, Japan). Genotyping was performed by the RIKEN institute (Wako, Japan) using the multiplex PCR-based invader assay (Third Wave Technologies, Madison, WI) as described previously [38].

\section{Statistical analysis}

Differences in the distribution of each characteristic variable between individuals with and without CKD were examined by the Student's $t$-test or $\chi^{2}$ test. Accordance with HWE, indicating an absence of discrepancy between genotype and allele frequencies, was determined using the $X^{2}$ test. Logistic regression analysis was performed to estimate age- and sex-adjusted ORs and 95\% CIs for CKD by genotype. All other potential confounding variables, including BMI, systolic blood pressure, diastolic blood pressure, fasting plasma glucose, glycated hemoglobin, total cholesterol, HDL cholesterol, triglycerides, uric acid, past history of cardiovascular or cerebrovascular diseases, use of anti-hypertensive, glucose-lowering, or lipid-lowering drugs, smoking status, and drinking habit were tested [39] to determine if they produced significant CIEs, as described previously [40,41].

We next evaluated the interaction term for effect measure modification using the B-D test of homogeneity with $\alpha=0.05$ [42]. Using the variables extracted by the process above, gene-environment interactions were assessed by the logistic model, which included a multiplicative interaction term as well as variables for genotypes, environment factors, age, and sex. Age adjustments in the analyses were performed with ages regarded as continuous variables. Analyses by genotype based on per allele model were carried out with genotypes for each polymorphism coded as ordinal-categorical variables according to the number of minor alleles. Differences of serum lipid levels by genotype were analyzed with Kruskal-Wallis test. All $P$ values were two-sided, and all calculations were performed using Stata $^{\circledR}$ version 10 software (StataCorp, College Station, TX).

\section{Additional files}

Additional file 1: Table S1. Estimated haplotype frequencies of APOA5 SNPs T-1131C (rs662799) and T1259C (rs2266788) and risk of CKD.

Additional file 2: Table S2. Lipid profiles according to genotypes of APOA5 and TOMM4O.

Additional file 3: Table S3. Exhaustive interaction analyses for the CKD risk between all tested polymorphisms and lifestyle factors.

\begin{abstract}
Abbreviations
CKD: Chronic kidney disease; HDL-C: High-density lipoprotein cholesterol; SCr: Serum creatinine; APOA5: Apolipoprotein A5; CETP: Cholesteryl ester transfer protein; LPL: Lipoprotein lipase; TOMM40: Translocase of the outer mitochondrial membrane 40; OR: Odds ratio; Cl: Confidence interval.
\end{abstract}

\section{Competing interests}

The authors declare that they have no competing interests.

\section{Authors' contributions}

$\mathrm{AH}$ did the data analysis and drafted the manuscript. KW, NH and HT designed and supervised the study. MK conducted the genotyping of the entire study subjects. MN, S. Suma, TS, SH, MH, TCT, S. Suzuki, TSK, HM, KO, IW and HU all contributed to the collection of data. All authors read and approved the final manuscript.

\section{Authors' information}

We all agree that every author is the co-first author of the paper.

\section{Acknowledgments}

We thank Kyota Ashikawa, Tomomi Aoi, and other members of the Core for Genomic Medicine, Center for Integrative Medical Sciences, RIKEN for support with genotyping in the study, Yoko Mitsuda, Keiko Shibata, and Etsuko Kimura at the Department of Preventive Medicine of Nagoya University Graduate School of Medicine, Miki Watanabe and Isao Oze at the Division of Epidemiology and Prevention of the Aichi Cancer Center Research Institute, Fusako Katsurada at the Department of Health Science of Shiga University of Medical Science, and Mitsuhiko Matsushita and Yasunobu Sagara at the Tokushima Prefecture Health Examination Center for their cooperation, technical assistance, and valuable comments. This study was supported in part by Grant-in-Aid for Scientific Research on Priority Areas of Cancer (No. 17015018) and on Innovative Areas (No. 221S0001) from the Ministry of Education, Culture, Sports, Science and Technology of Japan. 


\section{Author details}

${ }^{1}$ Department of Preventive Medicine, Nagoya University Graduate School of Medicine, Nagoya 466-8550, Japan. ²Department of Healthcare Administration, Nagoya University Graduate School of Medicine, Nagoya 466-8550, Japan. ${ }^{3}$ Division of Epidemiology and Prevention, Aichi Cancer Center Research Institute, Nagoya 464-8681, Japan. ${ }^{4}$ Department of Preventive Medicine, Faculty of Medicine, Saga University, Saga 849-8501, Japan. ${ }^{5}$ Department of Health Science, Shiga University of Medical Science, Otsu 520-2192, Japan. 'Department of Family Medicine, University of Calgary, Calgary, AB T2N 1N4, Canada. ${ }^{7}$ Department of Public Health, Nagoya City University Graduate School of Medical Sciences, Nagoya 467-8601, Japan. ${ }^{8}$ Department of International Island and Community Medicine, Kagoshima University Graduate School of Medical and Dental Sciences, Kagoshima 890-8544, Japan. ${ }^{~}$ Department of Community Medicine, Faculty of Medicine, Sam Ratulangi University, Manado 95115, Indonesia. ${ }^{10}$ Division of Epidemiology, Chiba Cancer Center Research Institute, Chiba 260-8717, Japan. ${ }^{11}$ Department of Geriatric Medicine, Graduate School of Medical Sciences, Kyushu University, Fukuoka 812-8582, Japan. ${ }^{12}$ Department of Social Medicine and Cultural Sciences, Kyoto Prefectural University of Medicine, Kyoto 602-8566, Japan. ${ }^{13}$ Department of Preventive Medicine, Institute of Health Biosciences, University of Tokushima Graduate School, Tokushima 770-8503, Japan. ${ }^{14}$ Core for Genomic Medicine, Center for Integrative Medical Sciences, RIKEN, Yokohama 230-0045, Japan.

Received: 18 July 2014 Accepted: 7 October 2014

Published: 14 October 2014

\section{References}

1. Nagata M, Ninomiya T, Doi Y, Yonemoto K, Kubo M, Hata J, Tsuruya K, lida M, Kiyohara Y: Trends in the prevalence of chronic kidney disease and its risk factors in a general Japanese population: the Hisayama Study. Nephrol Dial Transplant 2010, 25:2557-2564.

2. Tangri N, Kitsios GD, Inker LA, Griffith J, Naimark DM, Walker S, Rigatto C, Uhlig K, Kent DM, Levey AS: Risk prediction models for patients with chronic kidney disease: a systematic review. Ann Intern Med 2013, 158:596-603.

3. Kasiske BL, O'Donnell MP, Garvis WJ, Keane WF: Pharmacologic treatment of hyperlipidemia reduces glomerular injury in rat 5/6 nephrectomy model of chronic renal failure. Circ Res 1988, 62:367-374.

4. Kasiske BL, O'Donnell MP, Schmitz PG, Kim Y, Keane WF: Renal injury of diet-induced hypercholesterolemia in rats. Kidney Int 1990, 37:880-891.

5. Schaeffner ES, Kurth T, Curhan GC, Glynn RJ, Rexrode KM, Baigent C, Buring JE, Gaziano JM: Cholesterol and the risk of renal dysfunction in apparently healthy men. J Am Soc Nephrol 2003, 14:2084-2091.

6. Mänttäri M, Tiula E, Alikoski T, Manninen V: Effects of hypertension and dyslipidemia on the decline in renal function. Hypertension 1995, 26:670-675

7. Weycker D, Nichols GA, O'Keeffe-Rosetti M, Edelsberg J, Vincze G, Khan ZM, Oster G: Risk of chronic kidney disease in hypertensive patients with other metabolic conditions. J Hum Hypertens 2008, 22:132-134.

8. Hamajima N, J-MICC Study Group: The Japan Multi-Institutional Collaborative Cohort Study (J-MICC Study) to detect gene-environment interactions for cancer. Asian Pac J Cancer Prev 2007, 8:317-323.

9. Wakai K, Hamajima N, Okada R, Naito M, Morita E, Hishida A, Kawai S, Nishio K, Yin G, Asai Y, Matsuo K, Hosono S, Ito H, Watanabe M, Kawase T, Suzuki T, Tajima K, Tanaka K, Higaki Y, Hara M, Imaizumi T, Taguchi N, Nakamura K, Nanri H, Sakamoto T, Horita M, Shinchi K, Kita Y, Turin TC, Rumana N, et al: Profile of Participants and Genotype Distributions of 108 Polymorphisms in a Cross-sectional Study to Elucidate Associations between Genotypes and Lifestyle and Clinical Factors: A Project in the Japan Multi-institutional Collaborative Cohort (J-MICC) Study. J Epidemiol 2010, 21:223-235.

10. Hishida A, Morita E, Naito M, Okada R, Wakai K, Matsuo K, Nakamura K, Takashima N, Suzuki S, Takezaki T, Mikami H, Ohnaka K, Watanabe Y, Uemura H, Kubo M, Tanaka H, Hamajima N: Associations of apolipoprotein A5 (APOA5), glucokinase (GCK) and glucokinase regulatory protein (GCKR) polymorphisms and lifestyle factors with the risk of dyslipidemia and dysglycemia in Japanese - a cross-sectional data from the J-MICC Study. Endocr J 2012, 59:589-599.

11. Liu ZK, Hu M, Baum L, Thomas GN, Tomlinson B: Associations of polymorphisms in the apolipoprotein A1/C3/A4/A5 gene cluster with familial combined hyperlipidaemia in Hong Kong Chinese. Atherosclerosis 2010, 208:427-432.

12. Xu C, Bai R, Zhang D, Li Z, Zhu H, Lai M, Zhu Y: Effects of APOA5-1131 $T>C$ (rs662799) on fasting plasma lipids and risk of metabolic syndrome: evidence from a case-control study in China and a meta-analysis. PLoS One 2013, 8:e56216.

13. Massy ZA, Nguyen Khoa T, Lacour B, Descamps-Latscha B, Man NK, Jungers P: Dyslipidaemia and the progression of renal disease in chronic renal failure patients. Nephrol Dial Transplant 1999, 14:2392-2397.

14. Muntner P, Coresh J, Smith JC, Eckfeldt J, Klag MJ: Plasma lipids and risk of developing renal dysfunction: the atherosclerosis risk in communities study. Kidney Int 2000, 58:293-301.

15. Bagnoli S, Piaceri I, Tedde A, Bessi V, Bracco L, Sorbi S, Nacmias B: TOMM40 polymorphisms in Italian Alzheimer's disease and frontotemporal dementia patients. Neurol Sci 2013, 34:995-998.

16. Jiang $R$, Brummett $B H$, Hauser ER, Babyak MA, Siegler IC, Singh A, Astrup A Pedersen O, Hansen T, Holst C, Sørensen TI, Williams RB: Chronic family stress moderates the association between a TOMM40 variant and triglyceride levels in two independent Caucasian samples. Biol Psychol 2013, 93:184-189.

17. Zhang Z, Tao L, Chen Z, Zhou D, Kan M, Zhang D, Li C, He L, Liu Y: Association of genetic loci with blood lipids in the Chinese population. PLoS One 2011, 6:e27305

18. Lee MJ, Chien KL, Chen MF, Stephenson DA, Su TC: Overweight modulates APOE and APOA5 alleles on the risk of severe hypertriglyceridemia. Clin Chim Acta 2013, 416:31-35

19. Little J, Bradley L, Bray MS, Clyne M, Dorman J, Ellsworth DL, Hanson J, Khoury M, Lau J, O'Brien TR, Rothman N, Stroup D, Taioli E, Thomas D, Vainio $H$, Wacholder S, Weinberg C: Reporting, appraising, and integrating data on genotype prevalence and gene-disease associations. Am J Epidemiol 2002, 156:300-310.

20. Freeman DJ, Griffin BA, Holmes AP, Lindsay GM, Gaffney D, Packard CJ, Shepherd J: Regulation of plasma HDL cholesterol and subfraction distribution by genetic and environmental factors. Associations between the Taql B RFLP in the CETP gene and smoking and obesity. Arterioscler Thromb 1994, 14:336-344.

21. Dullaart RP, Sluiter WJ: Common variation in the CETP gene and the implications for cardiovascular disease and its treatment: an updated analysis. Pharmacogenomics 2008, 9:747-763.

22. Ordovas JM, Cupples LA, Corella D, Otvos JD, Osgood D, Martinez A, Lahoz C, Coltell O, Wilson PW, Schaefer EJ: Association of cholesteryl ester transfer protein-TaqIB polymorphism with variations in lipoprotein subclasses and coronary heart disease risk: the Framingham study. Arterioscler Thromb Vasc Biol 2000, 20:1323-1329.

23. Radovica I, Fridmanis D, Vaivade I, Nikitina-Zake L, Klovins J: The association of common SNPs and haplotypes in CETP gene with HDL cholesterol levels in Latvian population. PLoS One 2013, 8:e64191.

24. Thompson A, Di Angelantonio E, Sarwar N, Erqou S, Saleheen D, Dullaart RP, Keavney B, Ye Z, Danesh J: Association of cholesteryl ester transfer protein genotypes with CETP mass and activity, lipid levels, and coronary risk. JAMA 2008, 299:2777-2788.

25. Parsa A, Kao WH, Xie D, Astor BC, Li M, Hsu CY, Feldman HI, Parekh RS, Kusek JW, Greene TH, Fink JC, Anderson AH, Choi MJ, Wright JT Jr, Lash JP, Freedman BI, Ojo A, Winkler CA, Raj DS, Kopp JB, He J, Jensvold NG, Tao K, Lipkowitz MS, Appel L, AASK Study Investigators; CRIC Study Investigators: APOL1 risk variants, race, and progression of chronic kidney disease. N Engl J Med 2013, 369:2183-2196.

26. Ulasi II, Tzur S, Wasser WG, Shemer R, Kruzel E, Feigin E, ljoma CK, Onodugo OD, Okoye JU, Arodiwe EB, Ifebunandu NA, Chukwuka CJ, Onyedum CC, ljoma UN, Nna E, Onuigbo M, Rosset S, Skorecki K: High population frequencies of APOL1 risk variants are associated with increased prevalence of non-diabetic chronic kidney disease in the lgbo people from south-eastern Nigeria. Nephron Clin Pract 2013, 123:123-128.

27. Takeuchi F, Isono M, Katsuya T, Yokota M, Yamamoto K, Nabika T, Shimokawa K, Nakashima E, Sugiyama T, Rakugi H, Yamaguchi S, Ogihara T, Yamori Y, Kato N: Association of genetic variants influencing lipid levels with coronary artery disease in Japanese individuals. PLoS One 2012, 7:e46385.

28. Wang Q, Zhou SB, Wang L, Lei MM, Wang Y, Miao C, Jin YZ: Seven functional polymorphisms in the CETP gene and myocardial infarction risk: a meta-analysis and meta-regression. PLoS One 2014, 9:e88118. 
29. Seidell JC: Dietary fat and obesity: an epidemiologic perspective. Am J Clin Nutr 1998, 67(3 Suppl):546S-550S.

30. Bressler J, Pankow JS, Coresh J, Boerwinkle E: Interaction between the NOS3 Gene and Obesity as a Determinant of Risk of Type 2 Diabetes: The Atherosclerosis Risk in Communities Study. PLoS One 2013, 8:e79466.

31. Weinberg CR: Toward a clearer definition of confounding. Am J Epidemiol 1993, 137:1-8

32. Nakagawa S: A farewell to Bonferroni: the problem of low statistical power and publication bias. Behav Ecol 2004, 15:1044-1045.

33. Tokudome S, Goto C, Imaeda N, Tokudome Y, Ikeda M, Maki S:

Development of a data-based short food frequency questionnaire for assessing nutrient intake by middle-aged Japanese. Asian Pac J Cancer Prev 2004, 5:40-43.

34. Imaeda N, Goto C, Tokudome Y, Hirose K, Tajima K, Tokudome S: Reproducibility of a short food frequency questionnaire for Japanese general population. J Epidemiol 2007, 17:100-107.

35. Tokudome Y, Goto C, Imaeda N, Hasegawa T, Kato R, Hirose K, Tajima K, Tokudome S: Relative validity of a short food frequency questionnaire for assessing nutrient intake versus three-day weighed diet records in middle-aged Japanese. J Epidemiol 2005, 15:135-145.

36. Goto C, Tokudome Y, Imaeda N, Takekuma K, Kuriki K, Igarashi F, Ikeda M, Tokudome S: Validation study of fatty acid consumption assessed with a short food frequency questionnaire against plasma concentration in middle-aged Japanese people. Scand J Nutr 2006, 50:77-82.

37. Matsuo S, Imai E, Horio M, Yasuda Y, Tomita K, Nitta K, Yamagata K, Tomino Y, Yokoyama H, Hishida A, Collaborators developing the Japanese equation for estimated GFR: Revised Equations for Estimated GFR From Serum Creatinine in Japan. Am J Kidney Dis 2009, 53:982-992.

38. Ohnishi Y, Tanaka T, Ozaki K, Yamada R, Suzuki H, Nakamura Y: A high-throughput SNP typing system for genome-wide association studies. J Hum Genet 2001, 46:471-477.

39. Budtz-Jørgensen E, Keiding N, Grandjean P, Weihe P: Confounder selection in environmental epidemiology: assessment of health effects of prenatal mercury exposure. Ann Epidemiol 2007, 17:27-35.

40. Hishida A, Takashima N, Turin TC, Kawai S, Wakai K, Hamajima N, Hosono S, Nishida Y, Suzuki S, Nakahata N, Mikami H, Ohnaka K, Matsui D, Katsuura-Kamano S, Kubo M, Tanaka H, Kita Y: GCK, GCKR polymorphisms and risk of chronic kidney disease in Japanese individuals: data from the J-MICC Study. J Nephrol 2014, 27:143-149.

41. Hishida A, Okada R, Guang Y, Naito M, Wakai K, Hosono S, Nakamura K, Turin TC, Suzuki S, Niimura H, Mikami H, Otonari J, Kuriyama N, Katsuura S, Kubo M, Tanaka H, Hamajima N: MTHFR, MTR and MTRR polymorphisms and risk of chronic kidney disease in Japanese: cross-sectional data from the J-MICC Study. Int Urol Nephrol 2013, 45:1613-1620

42. Breslow NE, Day NE: Statistical Methods in Cancer Research: Volume 1 - The Analysis of Case-control Studies. International Agency for Research on Cancer: Lyon; 1980.

doi:10.1186/1476-511X-13-162

Cite this article as: Hishida et al:: Polymorphisms of genes involved in lipid metabolism and risk of chronic kidney disease in Japanese - crosssectional data from the J-MICC study. Lipids in Health and Disease 2014 13:162.

\section{Submit your next manuscript to BioMed Central and take full advantage of:}

- Convenient online submission

- Thorough peer review

- No space constraints or color figure charges

- Immediate publication on acceptance

- Inclusion in PubMed, CAS, Scopus and Google Scholar

- Research which is freely available for redistribution 